\title{
Tumor enucleation for Castleman's disease in the pulmonary hilum: a case report
}

\author{
Masaya Aoki (D), Go Kamimura, Tadashi Umehara, Aya Harada Takeda, Yui Watanabe, Koki Maeda, Toshiyuki Nagata, \\ Tsunayuki Otsuka and Masami Sato
}

\begin{abstract}
Background: The development of Castleman's disease in the pulmonary hilum is extremely rare. Although resection of only the lesion is sufficient because of its benign nature, lobectomy or more extensive procedures performed for the pulmonary hilar tumor have been reported.

Case presentation: The patient was a 15-year-old male with a tumor in the right pulmonary hilum. Endobronchial ultrasound-guided transbronchial needle aspiration was performed but no specific findings were obtained from the cytological and histological evaluation. 18F-fluorodeoxyglucose positron emission tomography showed moderate accumulation in the tumor, which suggested potential malignancy. Intraoperative frozen section diagnosis did not show any malignant findings. Thus, we performed only tumor enucleation without any lung resection. The pathological diagnosis was hyaline vascular type Castleman's disease. No recurrence has been observed for seven years.

Conclusion: Because hyaline vascular type Castleman's disease in solitary pulmonary hilar tumor is one of the benign diseases common in young people, intraoperative frozen section diagnosis is recommended to avoid unnecessary lung resection.
\end{abstract}

Keywords: Castleman's disease, Hyaline vascular type, Pulmonary hilum, Intraoperative frozen section diagnosis, Tumor enucleation

\section{Background}

Castleman's disease $(\mathrm{CD})$ is a rare disorder of lymph propagation first reported by Castleman and colleagues in 1954 from a case with chronic fever and mediastinal tumor [1]. Histologically, there are three types: hyaline vascular type (HV type), characterized by vessel hyperplasia with hyalinization; plasma cell type (PC type), characterized by plasma cell hyperplasia and cross follicles; and a mixed type with features of both types [2]. Clinically, the localized type is characterized by an enlarged lymph node centralized in one part. The multicentric type, first reported by Gaba and colleagues in 1978, shows lymph node enlargement throughout the body [3]. Treatment for localized type CD is usually surgical resection. Although resection of only the lesion is sufficient because of its benign nature, lobectomy or more extensive procedures performed for the pulmonary hilar

\footnotetext{
*Correspondence: masaya46@m.kufm.kagoshima-u.ac.jp Department of General Thoracic Surgery, Graduate School of Medical and Dental Sciences, Kagoshima University, 8-35-1 Sakuragaoka, Kagoshima 890-8520, Japan
}

\section{Case presentation}

A 15-year-old male without any symptoms was referred to our hospital because he was noted as having an abnormal shadow on chest X-ray at a health checkup. No abnormal findings were observed on his hematological and biochemical examinations. On chest computed tomography (CT), a $40 \times 33-\mathrm{mm}$ wide tumor shadow with clear boundaries in the right pulmonary hilar area was found. The tumor was strongly enhanced in the early phase. Abnormal findings were not found in the lung field and mediastinum (Fig. 1a-c). Bronchoscopic examination was performed under topical anesthesia. The lateral segment of the lower lobe of the right bronchus was narrowed by compression of the tumor although the endobronchial mucosa was intact. Endobronchial ultrasound-guided transbronchial needle aspiration (EBUS-TBNA) was performed but no specific findings were obtained from the 

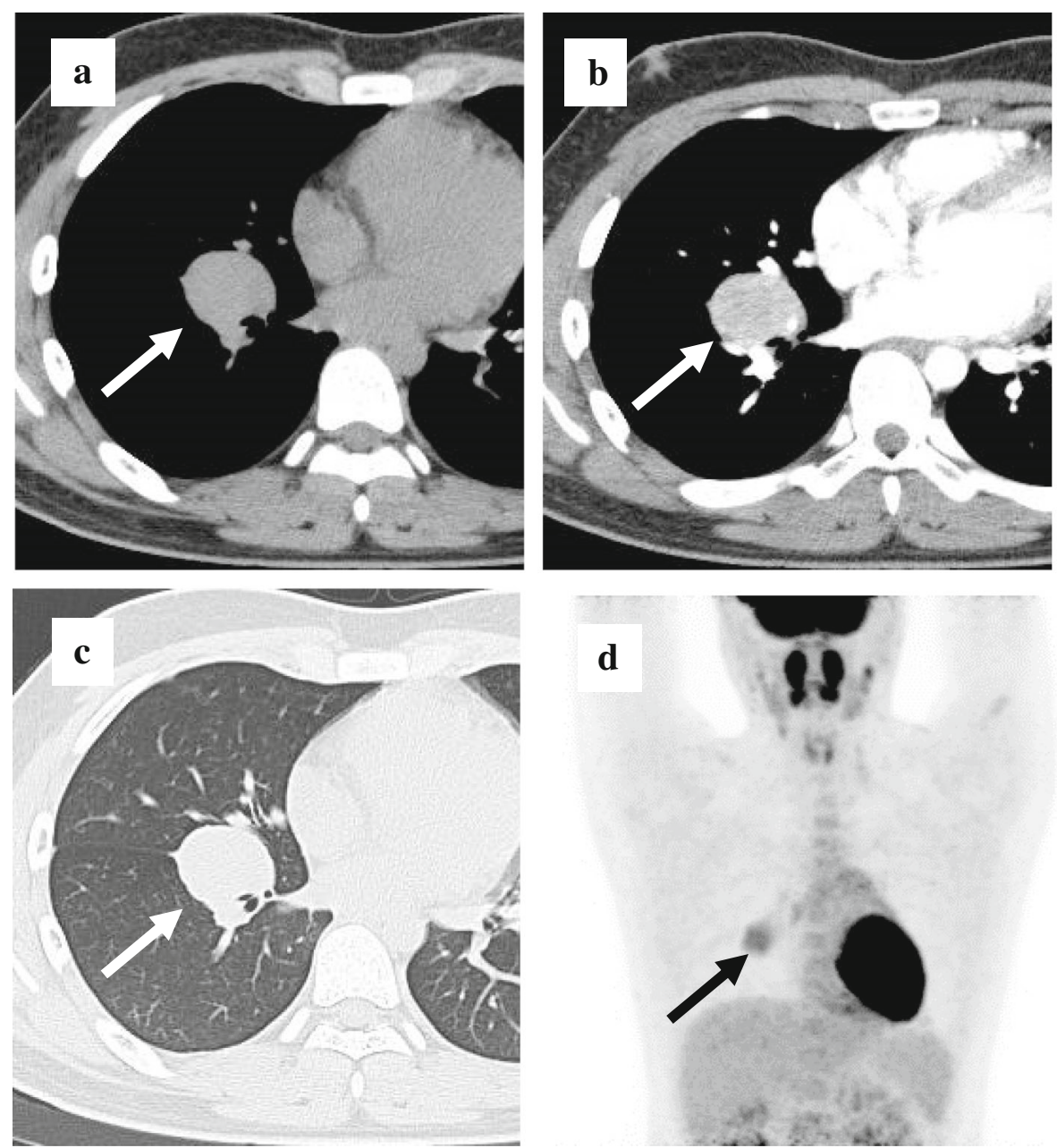

Fig. 1 Radiological findings. a Non-enhanced chest CT of mediastinal condition showed a 35-mm mass in the right pulmonary hilum (arrow). b In enhanced chest CT of mediastinal condition, the tumor was strongly enhanced in the early phase (arrow). c In nonenhanced chest CT of lung field condition, abnormal findings were not found in the lung field. $\mathbf{d}$ FDG-PET scan showed accumulation only in the mass (arrow)

cytological and histological evaluation. However, the patient was admitted to our department for surgery because 18F-fluorodeoxyglucose positron emission tomography (FDG-PET) showed abnormal accumulation in only the tumor; SUV (standard uptake value) max was 4.4 (Fig. 1d), which suggested potential malignancy. Due to the possibility of a malignant tumor, right middle and lower lobectomy was necessary due to its localization, and depending on the intraoperative findings, it was also necessary to perform right pneumonectomy. We informed the patient and his mother of this before surgery and obtained their consent. However, from the imaging morphology of the tumor and lack of evidence of malignancy in EBUS-TBNA, we also kept in mind before surgery the possibility of benign tumors including Castleman's disease. We decided to make a final decision on the procedure based on the findings of the intraoperative macroscopic findings and the intraoperative frozen section diagnosis.

On operative findings, the tumor existed between the middle and lower lobes of the right lung with no pleural involvement. The interlobar pulmonary artery was revealed on the back side of the tumor. We performed 18Ga needle biopsy for intraoperative frozen section diagnosis, which showed only chronic inflammation findings. Moreover, macroscopically, no tumor invasion into the pulmonary vessels, bronchi, and lung parenchyma was found. Therefore, only the tumor enucleation was performed (Fig. 2a). An intraoperative frozen section diagnosis of the removed tumor found suspected Castleman's disease. Therefore, we decided not to do further resection. 

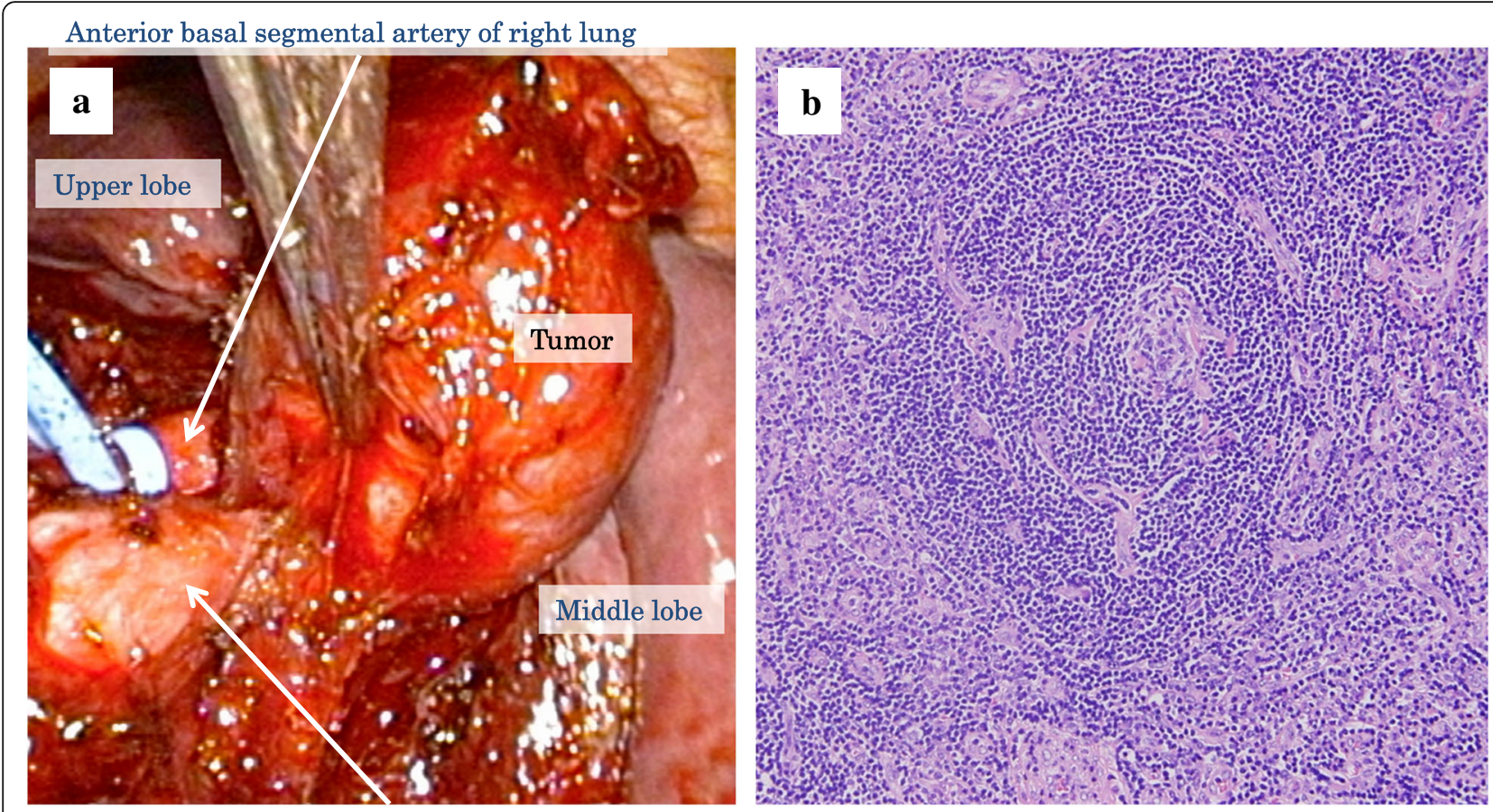

Anterior basal segmental bronchus of right lung

Fig. 2. Operative findings and histological findings. a The tumor existed between middle and lower lobe of the right lung. Because no tumor invasion into the pulmonary artery and/or lung parenchyma were found, only the tumor enucleation was carried out. b There were clearly hyalinizing concentric fibrotic nests around the lymph follicle and vessel hyperplasia on the hyalinizing wall. There were almost no plasma cells outside the follicle. Histological diagnosis was HV type CD

The extirpated specimen was a $30 \times 23-\mathrm{mm}$ smooth and well-encapsulated tumor. Histologically, the lesion had a fibrous capsule with clear boundaries consisting of lymph follicle hyperplasia. There were clearly hyalinizing concentric fibrotic nests around the lymph follicle and vessel hyperplasia on the hyalinizing wall. There were almost no plasma cells outside the follicle. Histological diagnosis was that of $\mathrm{HV}$ type $\mathrm{CD}$ (Fig. 2b). The postoperative course was good, there were no complications, and he was discharged home on the fifth postoperative day. The patient is now under follow-up observation with no recurrence seven years after the operation.

HV type CD is common in young people. The most common sites of this disease are in the cervix, mediastinum, abdomen, and retroperitoneum [4], but it is very rare in the pulmonary hilum. HV type CD is usually discovered by chance in regular health checkups with almost no accompanying specific symptoms. In radiological findings, enhanced CT shows a contrasted tumor with clear boundaries in general, especially in the HV type. High contrast is promptly recommended for vessel hyperplasia with hyalinizing inside the tumor [5]. In addition, some reports recently found that FDG-PET sometimes shows light-to-moderate accumulation [6-8]. However, in any case, the findings are not specific for $\mathrm{CD}$, making it very difficult to reach the diagnosis by radiological findings alone. Moreover, from the reports so far, definitive diagnosis by preoperative biopsy seems difficult [9-12]. Similarly, the preoperative diagnosis of our case could not be made because of insufficient biopsy specimens for the pulmonary hilar mass.

Keller et al. retrospectively examined six localized HV type $C D$ patients who received partial resection, biopsy, or observation alone. They reported that disease progression was noted at four years after surgery in one patient and, in another patient, complete resection was performed eight years after an initial biopsy and observation following the onset of symptoms [2]. Moreover, Biçakçioğlu et al. reported that 17 of the $19 \mathrm{CD}$ cases, including seven cases in the pulmonary hilum, in which surgery was performed were localized, and that 15 cases in which complete resection was performed had no recurrence [12]. Therefore, the recommended treatment strategy for localized $\mathrm{HV}$ type $\mathrm{CD}$ is complete resection. We found ten cases of resection of $\mathrm{HV}$ type $\mathrm{CD}$ in the pulmonary hilum in which detailed clinical information including surgical procedure could be obtained from the articles searched with the terms: Castleman's disease AND pulmonary AND surgery in PubMed (Table 1) [9-11, 13-19]. One case 
Table 1 Operative procedures and intraoperative biopsies in previously reported cases

\begin{tabular}{|c|c|c|c|c|c|c|}
\hline Author & Age & Sex & Preoperative biopsy & Intraoperative biopsy & Procedure & $\begin{array}{l}\text { Cause of lobectomy or } \\
\text { more extensive surgery }\end{array}$ \\
\hline Yeh & 42 & M & Not done & Not done & LUL & Potential malignancy \\
\hline Tokunaga & 23 & $\mathrm{~F}$ & Not done & Not done & $L L L+M L N D$ & Potential malignancy \\
\hline Racil & 23 & $\mathrm{~F}$ & Not done & Not done & Pneumonectomy & $\begin{array}{l}\text { Bleeding at intraoperative } \\
\text { biopsy }\end{array}$ \\
\hline Wang & 27 & M & Not done & Not done & Enucleation & - \\
\hline Gunluogle & 29 & M & TBNA: no specific findings & Benign & Enucleation & - \\
\hline Ota & 19 & M & Not done & Not done & RML & Not mentioned \\
\hline Nadir & 28 & $\mathrm{~F}$ & Not done & Not done & $R U L+M L N D$ & $\begin{array}{l}\text { Adhesion and } \\
\text { hypervascularity }\end{array}$ \\
\hline Liu & 32 & M & Not done & Not done & $L U L+M L N D$ & Potential malignancy \\
\hline Haager & 24 & M & EBUS-TBNA: no specific findings & $\begin{array}{l}\text { Lymphoma or } \\
\text { carcinoid }\end{array}$ & RML & Not mentioned \\
\hline Luo & 40 & $\mathrm{~F}$ & TBNA: chronic inflammation & Not mentioned & Whole resection & - \\
\hline Present case & 16 & M & EBUS-TBNA: no specific findings & Chronic inflammation & Enucleation & - \\
\hline
\end{tabular}

EBUS endobronchial ultrasound-guided, TBNA transbronchial needle aspiration, LUL left upper lobectomy, LLL left lower lobectomy, RML right middle lobectomy, $R U L$ right upper lobectomy, MLND mediastinal lymph node dissection

reported by Luo et al. was described as "whole resection" and the details were unknown about surgical procedure [11]. Lobectomy or more extensive surgery was performed in seven of these nine cases. In only one of seven cases was intraoperative frozen section diagnosis performed [10]. In three of six cases, lobectomy was performed because malignancy of the tumor could not be ruled out $[13,14,19]$. Moreover, in the other case, there was no mention in the article why lobectomy was performed [17]. If intraoperative frozen section diagnosis was performed on these four cases with benign diseases as in this present case of $\mathrm{CD}$, it may have been possible to select a procedure that would have preserved pulmonary function. Tumor enucleation was performed in two cases. In one of two cases, intraoperative frozen section diagnosis was performed [9]. We performed only tumor enucleation considering both the localized FDG-PET accumulation and the intraoperative frozen section diagnosis without major bleeding to carefully separate the tumor from surrounding tissue. The patient is now under follow-up observation with no recurrence seven years after the operation."

\section{Conclusion}

In young patients with isolated solitary pulmonary hilar tumor that does not lead to a diagnosis before surgery, intraoperative frozen section diagnosis should be performed to consider the possibility of $\mathrm{CD}$. If malignant findings are not recognized in intraoperative frozen section diagnosis, the choice of procedures that preserve pulmonary function as much as possible is desirable because $\mathrm{CD}$ is a benign disease commonly seen in young people. However, an accumulation of cases with such localized HV type CD in the pulmonary hilum will be required to determine whether surgical mode of only tumor enucleation with long followup term is medically satisfactory.

\section{Abbreviations \\ CD: Castleman's disease; CT: Computed tomography; EBUS- TBNA: Endobronchial ultrasound-guided transbronchial needle aspiration; FDG-PET: 18F-fluorodeoxyglucose positron emission tomography; HV type: Hyaline vascular type; LLL: Left lower lobectomy; LUL: Left upper lobectomy; MLND: Mediastinal lymph node dissection; PC type: Plasma cell type; RML: Right middle lobectomy; RUL: Right upper lobectomy; SUV: Standard uptake value}

\section{Acknowledgements}

We would like to thank Dr. Mark Snape for English language editing.

\section{Authors' contributions}

MA is the first and corresponding author of this manuscript. MA, TO, and MS participated in the operation of this case. MA, GK, TU, AHT, YW, TO, and KM treated the patient after the operation. MS supervised the operation and the editing of the manuscript, MA drafted the manuscript, and all authors read and approved the final manuscript.

\section{Funding}

None of the authors have anything to disclose.

Availability of data and materials

The datasets supporting the conclusions of this article are included within the article.

Ethics approval and consent participate

Not applicable

\section{Consent for publication}

Written informed consent was obtained from the patient and his mother for publication of this case. 


\section{Competing interests}

The authors declare that they have no competing interests.

Received: 30 January 2019 Accepted: 29 May 2019

Published online: 10 June 2019

\section{References}

1. Castleman B, Towne WW. Case records of the Massachusetts General Hospital: Case No. 40231. N Engl J Med. 1954;250:1001-5.

2. Keller AR, Hochholzer L, Castleman B. Hyaline-vascular and plasma-cell types of giant lymph node hyperplasia of the mediastinum and other locations. Cancer. 1972;29:670-83.

3. Gaba AR, Stein RS, Sweet DL, Variakojis D. Multicentric giant lymph node hyperplasia. Am J Clin Pathol. 1978;69:86-90.

4. Danon AD, Krishnan J, Frizzera G. Morpho-immuno-phenotypic diversity of Castleman's disease, hyaline-vascular type: with emphasis on a stroma-rich variant and a new pathogenetic hypothesis. Virchows Arch A Pathol Anat Histopathol. 1993;423:369-82.

5. Moon WK, Im JG, Kim JS, Choi CG, Kim HC, et al. Mediastinal Castleman disease: CT findings. J Comput Assist Tomogr. 1994;18:43-6.

6. Kunishima S, Taniguchi H, Koh T, Yamaguchi A, Yamagishi H. F-18 fluorodeoxyglucose positron emission tomography in mesenterial Castleman's lymphoma. Clin Nucl Med. 2001;26:789-90.

7. Reddy MP, Graham MM. FDG positron emission tomographic imaging of thoracic Castleman's disease. Clin Nucl Med. 2003;28:325-6.

8. Enomoto K, Nakamichi I, Hamada K, Inoue A, Higuchi I, et al. Unicentric and multicentric Castleman's disease. Br J Radiol. 2007;80:e24-6.

9. Gunluoglu G, Olcmen A, Sokucu SN, Akin H, Dincer I. Intrapulmonarylocated Castleman's disease, which was surgically resected without pulmonary resection. Ann Thorac Cardiovasc Surg. 2011;17:580-3.

10. Haager B, Kayser G, Schmid S, Passlick B, Wiesemann S. Intrapulmonary Castleman's disease pretending to be a lung cancer-work up of an intrapulmonary tumour. Ann Thorac Cardiovasc Surg. 2016;22:258-60.

11. Luo JM, Li S, Huang H, Cao J, Xu K, et al. Clinical spectrum of intrathoracic Castleman disease: a retrospective analysis of 48 cases in a single Chinese hospital. BMC Pulm Med. 2015;15:34.

12. Biçakçioğlu P, Gülhan S\$, Acar LN, Ağaçkiran Y, Özkara \$, et al. Intrathoracic Castleman disease. Turk J Med Sci. 2014;44:197-202.

13. Yeh CM, Chou CM, Wong LC. Castleman's disease mimicking intrapulmonary malignancy. Ann Thorac Surg. 2007;84:e6-7.

14. Tokunaga T, Kadota Y, Utsumi T, Inoue M, Minami M, et al. Castleman's disease arising from an intrapulmonary lymph node. Gen Thorac Cardiovasc Surg. 2009;57:562-5.

15. Racil H, Cheikh Rouhou S, Ismail O, Hantous-Zannad S, Chaouch N, et al. Castleman's disease: an intrapulmonary form with intrafissural development. ScientificWorldJournal. 2009;9:940-5.

16. Wang SH, Ruan Z, Huang HL, Song KS. A rare case of Castleman disease presenting as pulmonary mass mimicking central pulmonary malignancy. Chin Med J (Engl). 2009;122:990-1.

17. Ota H, Kawai H, Matsuo T. Unicentric Castleman's disease arising from an intrapulmonary lymph node. Case Rep Surg. 2013;2013:289089.

18. Nadir A, Colak N, Koktener A, Yildirim U. Isolated intrapulmonary Castleman's disease: a case report, review of the literature. Ann Thorac Cardiovasc Surg. 2014;20:Suppl:689-91.

19. Liu Y, Chen G, Qiu X, Xu S, Wu Y, et al. Intrapulmonary unicentric Castleman disease mimicking peripheral pulmonary malignancy. Thorac Cancer. 2014;5: $576-80$

\section{Publisher's Note}

Springer Nature remains neutral with regard to jurisdictional claims in published maps and institutional affiliations.

\section{Submit your manuscript to a SpringerOpen ${ }^{\circ}$ journal and benefit from:}

- Convenient online submission

- Rigorous peer review

- Open access: articles freely available online

High visibility within the field

- Retaining the copyright to your article

Submit your next manuscript at $\boldsymbol{\nabla}$ springeropen.com 